\title{
ORIGINAL ARTICLE Long-term treatment of phenylketonuria with a new medical food containing large neutral amino acids
}

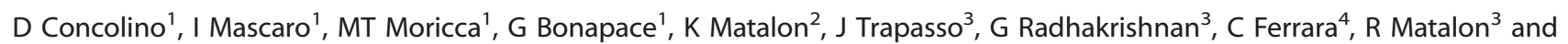 \\ P Strisciuglio ${ }^{5}$
}

BACKGROUND/OBJECTIVES: Phenylketonuria (PKU) is an autosomal recessive disease caused by deficient activity of phenylalanine hydroxylase. A low phenylalanine (Phe) diet is used to treat PKU. The diet is very restrictive, and dietary adherence tends to decrease as patients get older. Methods to improve dietary adherence and blood Phe control are continuously under investigation. SUBJECTS/METHODS: A new formula Phe-neutral amino acid (PheLNAA) has been tested in this study with the purpose of improving the compliance and lowering blood phenylalanine. The formula has been tested for nitrogen balance, and it is nutritionally complete. It is fortified with more nutritional additives that can be deficient in the PKU diet, such as B12, Biotin, DHA, Lutein and increased levels of large neutral amino acids to help lower blood Phe. The new formula has been tested on 12 patients with a loading test of 4 weeks.

RESULTS: Fifty-eight percent of patients had a significant decline in blood Phe concentration from baseline throughout the study. The PheLNAA was well tolerated with excellent compliance and without illnesses during the study.

CONCLUSIONS: In conclusion, the new formula is suitable for life-long treatment of PKU, and it offers the PKU clinic a new choice for treatment.

European Journal of Clinical Nutrition (2017) 71, 51-55; doi:10.1038/ejcn.2016.166; published online 14 September 2016

\section{INTRODUCTION}

Phenylketonuria (PKU) is caused by deficiency of the enzyme phenylalanine hydroxylase (PAH). This enzyme deficiency results in the inability to convert Phe to tyrosine, leading to an increased concentration of phenylalanine in the blood and central nervous system. The clinical features of untreated PKU include mental retardation, pigment dilution, microcephaly, seizure disorder and eczema. ${ }^{1}$ A diet restricted in phenylalanine (Phe) improved the clinical outcome of patients with PKU in the early trials of Bickel et $a l^{2}$ The National Collaborative Study for PKU documented safe blood Phe concentrations for treatment and determined that discontinuing diet treatment around the age of 6 years leads to a decline in intelligence quotient, poor school performance, decline in executive functioning and changes in the white matter of the brain. $^{3-18}$ This resulted in reassessment of the diet discontinuation policy, and the concept of 'diet for life' emerged.

Treatment for PKU with Phe-free medical food and measured servings of foods with low protein should be continued for life. Items such as low-protein bread, noodles or cookies, sodas and hard candy can be used as fillers. The blood Phe concentration often increases above the desired treatment goal as patients get older because of the limited number and serving sizes of foods available for older children on the diet. Continued efforts are being made to improve treatment for patients with PKU to better regulate blood Phe levels.

A synthetic version of tetrahydrobiopterin $(\mathrm{BH} 4)$, the cofactor for $\mathrm{PAH}$, can reduce Phe levels in about one-third of patients with PKU. ${ }^{19}$ This can result in improved concentration and executive functioning, but even with $\mathrm{BH} 4$ supplementation blood Phe levels can remain above levels targeted, and dietary treatment should be continued. ${ }^{20}$

Large neutral amino acids (LNAA) can be added to the medical food to compete with Phe for the same transporter in the gastrointestinal (Gl) tract and blood-brain barrier (BBB). ${ }^{21}$ A new medical food, PheLNAA, was developed with higher concentrations of LNAA fortified with vitamins that are more abundant in high-protein foods. Other nutrients include Lutein, an antioxidant found in high concentration in the retina, and microalgae docosahexaenoic acid (DHA), important for the development of the brain. Increased amounts of biotin, vitamin B12 and folate have also been added. This report investigates the acceptability, tolerance and blood Phe control of the new medical food, PheLNAA.

\section{MATERIALS AND METHODS}

Recruitment and study population

Subjects with PKU in dietary therapy were recruited from the Department of Pediatrics, University of Catanzaro, Italy, and were asked to participate in a research protocol to evaluate the acceptability and tolerance of a new medical food, PheLNAA, and its effectiveness in reducing the concentration of blood Phe. The criteria for inclusion in the study were a diagnosis of mild or classical PKU identified by neonatal screening, dietary therapy from the first month of life to the age of 8 years or older, baseline blood Phe concentration $>6 \mathrm{mg} / \mathrm{dl}(>360 \mu \mathrm{mol} / \mathrm{l})$ and intelligence quotient in the normal range. All patients in the study were genotyped according to Guzzetta et al. ${ }^{22}$ (Figure 1). The exclusion criteria were the presence of other diseases, malabsorption or women who may become pregnant. Eligible patients who agreed to participate, or their parents or legal representative, signed an informed consent form approved by the Institutional Review Board and Ethics Committee at the University of

\footnotetext{
${ }^{1}$ Department of Medical and Surgical Science, Pediatrics Unit, University 'Magna Graecia', Catanzaro, Italy; ${ }^{2}$ Department of Health and Human Performance, University of Houston, Houston, TX, USA; ${ }^{3}$ Department of Pediatrics, University of Texas Medical Branch, Galveston, TX, USA; ${ }^{4}$ Department of Public Health and Infectious Diseases, Sapienza University, Rome, Italy and ${ }^{5}$ Department of Translational medical Science, Section of Pediatrics, Federico II University, Naples, Italy. Correspondence: Professor P Strisciuglio, Department of Pediatrics, Federico II University, via S. Pansini, 5, Naples 80131, Italy.

E-mail: pietro.strisciuglio@unina.it

Received 4 March 2016; revised 8 July 2016; accepted 31 July 2016; published online 14 September 2016
} 
Catanzaro. All procedures were in accordance with the ethical standards of the responsible committee on human experimentation and with the Helsinki Declaration of 1975, as revised in 1983.

\section{Study design}

Baseline values were established 3 weeks before the start of the study. During this time, weekly blood Phe and Tyrosine (Tyr) levels were taken $2 \mathrm{~h}$ postprandial, and dietary intake was recorded for 3 days before blood draw. These same measures were continued throughout the loading study period. A dietitian calculated the total dietary intake and recorded the dietary intake of Phe, Tyr, protein and energy; blood Phe and Tyr results were also recorded. Growth data and blood chemistry (electrolytes, BUN, total protein and albumin) were ascertained at the beginning and after 4 weeks of treatment.

A total of $0.5 \mathrm{~g} / \mathrm{kg} /$ day of the new medical food (Table 1), PheLNAA sachets, produced by MOVISCOM in Rome, Italy, was divided into three doses and administered before main meals for 4 weeks. No other special supplements were given to the patients. Patients who did not initially respond to the 4-weektreatment period continued to receive the study product for an additional 2 weeks to test whether a longer treatment would provide some result.

Each study subject was advised by a dietitian on how much Phe to take during the study. This dietitian then calculated the actual dietary intake of Phe and recorded the blood Phe and Tyr concentrations.

The primary end point was to decrease Phe levels by $30 \%$ or more from baseline and then to lower the Phe/Tyr ratio after 4 weeks (responders) or 6 weeks (not responders) of treatment.

Blood Phe and Tyr concentrations were taken and diet diaries accompanied blood specimens. Patients were instructed to contact the clinic for any illness or unusual complaints during the study.

\section{Statistical analysis}

Preliminarily, a descriptive analysis has been performed; in particular, averages, medians, s.d., range and percentage variation of the variables considered in the observation times have been computed.

Subsequently, noting the non-compliance of the data to the normal distribution and also taking into account the small sample size, it was decided to use non-parametric statistical tests. In particular, for the assessment of the variations between the two times, we applied the statistical test based on ranks for paired data of Wilkoxon. As usual, it fixed an error of the first type $(\alpha)$ equal to 0.05 , therefore considering as significant those tests presenting a $P<0.05$.

Analyses were performed with 'SPSS Statistics', IBM, Armonk, NY, USA.

\section{RESULTS}

Sixteen patients participated in the trial. Four patients dropped out after the first week because of non-compliance with the study protocol. The remaining 12 patients (three with mild PKU and nine with classic PKU, three males and nine females), with a mean age of 14.8 years, were analyzed (Table 2 ). The patients were of a mean height of $149.25 \mathrm{~cm}( \pm 14.21)$, in a range of 49 , and a mean weight of $45.53 \mathrm{~kg}( \pm 12.17)$ (whereas the median weight was $47.15 \mathrm{in}$ a

\begin{tabular}{|c|c|c|c|c|c|}
\hline & & & Vitamins & & \\
\hline \multirow[t]{6}{*}{ Energy } & kcal & 293.50 & A & $\mathrm{mcg}$ & 1300 \\
\hline & $\mathrm{kJ}$ & 1241.26 & $D_{3}$ & mcg & 15.5 \\
\hline & & & $\mathrm{E}$ & $\mathrm{mg}$ & 20 \\
\hline & & & K1 & $\mathrm{mcg}$ & 113 \\
\hline & & & $C$ & $\mathrm{mg}$ & 100 \\
\hline & & & $\mathrm{B}_{1}$ & $\mathrm{mg}$ & 1.5 \\
\hline Protein equivalent & $\mathrm{g}$ & 48.94 & $\mathrm{~B}_{2}$ & $\mathrm{mg}$ & 1.8 \\
\hline Carbohydrates & $\mathrm{g}$ & 15.74 & $\mathrm{~B}_{6}$ & $\mathrm{mg}$ & 5.4 \\
\hline Sugars & $\mathrm{g}$ & 12.46 & $B_{12}$ & $\mathrm{mcg}$ & 9 \\
\hline Fats & $\mathrm{g}$ & 2.58 & Biotin & mcg & 150 \\
\hline DHA & $\mathrm{mg}$ & 610 & Choline & $\mathrm{mg}$ & 650 \\
\hline Amino Acids & $\mathrm{g}$ & & Inositol & $\mathrm{mg}$ & 125 \\
\hline Arginine & $\mathrm{g}$ & 61.73 & Niacin & $\mathrm{mg}$ & 20 \\
\hline Aspartic Acid & g & 2.79 & Folic acid & mcg & 750 \\
\hline Glutamine & g & 2.36 & $\begin{array}{l}\text { Pantothenic acid } \\
\text { Minerals }\end{array}$ & $\mathrm{mg}$ & 8.8 \\
\hline Isoleucine & $\mathrm{g}$ & 3.52 & Calcium & $\mathrm{mg}$ & 1600 \\
\hline Leucine & $\mathrm{g}$ & 3.33 & Chromium & $\mathrm{mcg}$ & 40 \\
\hline Lysine & $\mathrm{g}$ & 9.79 & Copper & $\mathrm{mg}$ & 1.5 \\
\hline Methionine & g & 5.70 & lodine & mcg & 200 \\
\hline Proline & $\mathrm{g}$ & 0.97 & Iron & $\mathrm{mg}$ & 20 \\
\hline Threonine & g & 3.45 & Magnesium & $\mathrm{mg}$ & 500 \\
\hline Tryptophan & $\mathrm{g}$ & 3.15 & Manganese & $\mathrm{mg}$ & 3 \\
\hline Tyrosine & $\mathrm{g}$ & 3.33 & Molybdenum & $\mathrm{mcg}$ & 90 \\
\hline Valine & g & 18.79 & Phosphorous & $\mathrm{mg}$ & 1250 \\
\hline \multirow[t]{4}{*}{ Hystidine } & $\mathrm{g}$ & 1.21 & Selenium & $\mathrm{mcg}$ & 75 \\
\hline & & & Sodium & $\mathrm{mg}$ & 40 \\
\hline & & & Zinc & $\mathrm{mg}$ & 15 \\
\hline & & & Lutein & $\mathrm{mg}$ & 12 \\
\hline
\end{tabular}

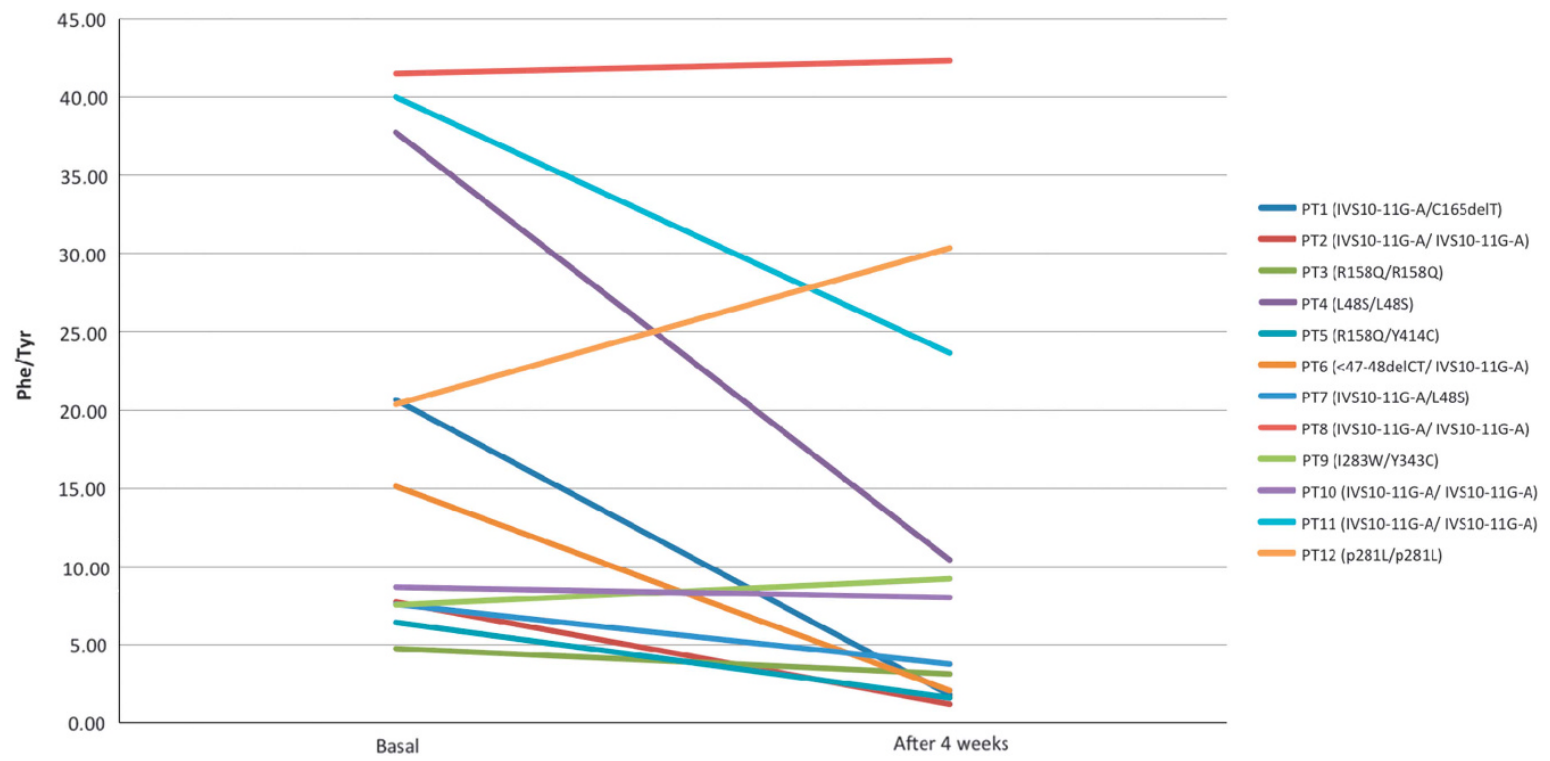

Figure 1. Phe/Tyr ratio at the basal time and after 4 weeks for the 12 patients; in the legend is shown (enclosed in parentheses) the genotype of each patient according to Guzzetta et al. ${ }^{22}$ 
range of 40). As regards the body mass index, the mean value was $20.21( \pm 3.21)$, in a range of 10.90 .

Table 3 shows that the blood Phe concentration decreased, from an average of 15.15, at the basal time (Phe T0), to 11.15 after 4 weeks of treatment (Phe T1), with a mean percentage variation of $-31.38 \%$. Moreover, we have tested the difference between Phe T0 and Phe T1, which gave statistically significant results $(P=0.033)$.

With regard to Tyrosine concentration, we have a basal mean value (Tyr T0) of 1.14, and a mean value of 1.63 after 4 weeks of treatment (Tyr T1). The mean percentage variation increased by $45.31 \%$, and also in this case the difference between Tyr T0 and Tyr T1 was statistically significant $(P=0.034)$.

Finally, we have analyzed the ratio between the level of Phe and Tyr at the basal time and after 4 weeks (Figure 1). We can observe a decrease in this ratio. In fact, the mean percentage variation is of $-39.18 \%$. The difference between the two ratio results was statistically significant at the level of 0.05 . No correlation was observed between the severity of mutations and response to PheLNAA supplementation.

In Figure 2, we have reported the level of Phe and Tyr at the basal time and after 4 weeks of treatment for each patient.

No patients showed intolerance or illness during the study, and growth remained normal for all children included in the study. The electrolytes, total protein and albumin remained normal before and at the end of the 4 weeks of therapy (data not shown).

\section{DISCUSSION}

Diet for life is the accepted treatment for PKU. The lack of diet adherence in the treatment of PKU is of concern. The NIH National Consensus Committee for Treatment of $\mathrm{PKU}^{23}$ in the United States most recently recommended target blood Phe concentrations of $<6 \mathrm{mg} / \mathrm{dl}(360 \mu \mathrm{mol} / \mathrm{l})$ for all ages. Difficulty in maintaining blood Phe in the recommended range in adolescents has been documented. ${ }^{4,6,7}$ Dietary treatment for PKU requires intake of a Phe-free medical food and measured servings of Phe-containing foods to maintain blood Phe concentrations in the desired treatment range. The amount and types of foods that can be eaten are limited, and this makes it difficult for adolescents to comply with diet. Methods to improve dietary adherence in PKU patients and improve blood Phe control are greatly needed.

This study utilized the newly formulated medical food, PheLNAA sachets. It contains increased concentrations of large neutral amino acids compared with other medical foods used for the treatment of PKU. In addition, it contains more vitamins and other nutritional additives that can be deficient in the PKU diet, such as vitamin B12, Biotin, DHA and Lutein. The LNAA can help reach target blood Phe levels by blocking some of the transport of Phe in the Gl tract and across the BBB. In the Gl tract, LNAA is transported by a carrier protein with $K_{\mathrm{m}}$ that is two orders of magnitude higher than that of the BBB carrier protein. ${ }^{24}$ According to the experiments of Hidalgo et al., ${ }^{24}$ a significant

Table 3. Descriptive analysis of the blood Phe and Tyr levels

\begin{tabular}{lrrrrc}
\hline & Mean & s.d. & Median & Range & $P$ \\
\hline Phe T0 & 15.15 & 6.34 & 16.20 & 15.70 & 0.033 \\
Phe T1 & 11.15 & 8.21 & 10.30 & 20.28 & \\
\% var Phe T1/T0 & -31.38 & 37.36 & -35.00 & 131.04 & \\
Tyr T0 & 1.14 & 0.64 & 0.92 & 1.87 & 0.034 \\
Tyr T1 & 1.63 & 1.26 & 1.30 & 4.54 & \\
\% var Tyr T1/T0 & 45.31 & 67.83 & 24.29 & 204.57 & \\
Phe T0/Tyr T0 & 18.18 & 14.04 & 11.90 & 36.77 & 0.050 \\
Phe T1/Tyr T1 & 11.45 & 13.45 & 5.87 & 41.11 & \\
\% var Phe/Tyr T1/T0 & -39.18 & 46.52 & -45.72 & 140.45 & \\
\hline
\end{tabular}



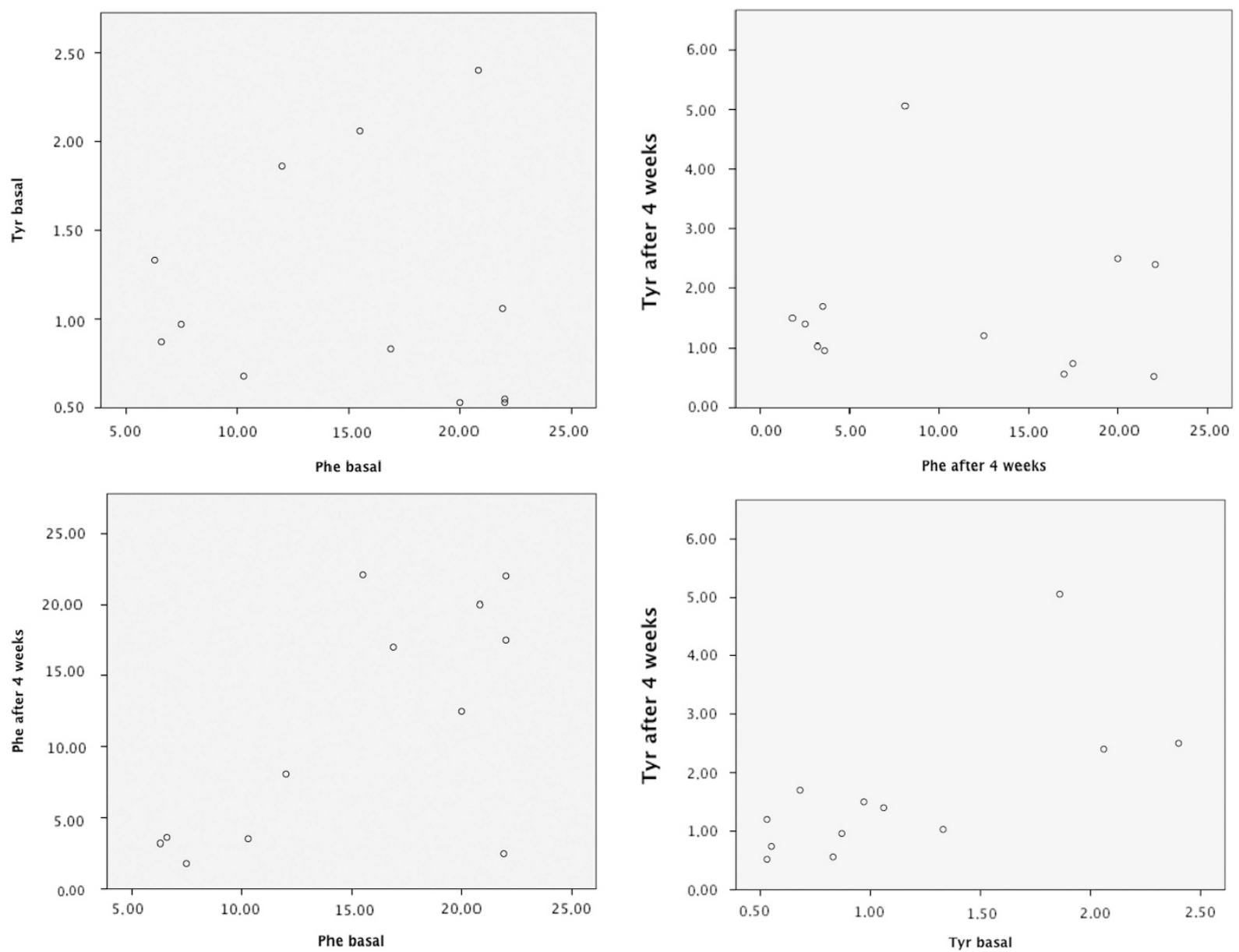

Figure 2. Phe and Tyr levels for each patient.

inhibition of Phe transport requires 100-fold (1 mM) LNAA, as dictated by the $K_{\mathrm{m}}$ equation for affinity of LNAA to the Gl carrier protein. For example, at such concentrations, leucine inhibits Phe transport by $55 \%$, tyrosine by $45 \%$ and the cationic amino acid lysine by $50 \% .{ }^{24}$ Under physiological conditions, competition of LNAA with Phe is not likely to occur in the GI tract. However, by increasing the concentration of LNAA and lysine, while the concentration of Phe is unchanged or reduced, competition with the GI transporter can be achieved. The transport of LNAA to the brain is mediated by a carrier protein with the lowest $K_{m}$ for Phe. The $K_{\mathrm{m}}$ equation predicts that if the plasma level of one of the large neutral amino acids has a lower $K_{\mathrm{m}}$, then that amino acid will not compete effectively for the carrier protein. ${ }^{25-28}$ There are reports on mice and some patients with PKU who have lower concentrations of tyrosine, tryptophan and branched chain amino acids $^{29}$ in the brain as a result of the elevated blood Phe crossing the BBB. This may be due to little competition from the other large neutral amino acids. Mice with PKU were shown to have leucine concentration that is lower in the brain because of the preference for Phe for transport across the BBB. When fed mouse chow with $16.7 \%$ LNAA, these mice had a statistically significant decrease in blood Phe concentration. ${ }^{30,31}$ This suggests that a competition with the transport of Phe can be attained with high levels of LNAA in the Gl tract, satisfying the concentrations required by $\mathrm{Km}$ for the Gl transporter.

In human patients with PKU, we have shown in a double-blind study that blood Phe concentration declines significantly when treated with LNAA. ${ }^{32}$ These studies suggest that adding increased dietary concentration of LNAA for patients with PKU will lead to a reduction in blood Phe concentrations. ${ }^{32}$

The current study utilized PheLNAA sachets, a new medical food that contains increased concentrations of LNAA, and includes some other nutrients needed for treatment of PKU, making it a more complete food (Table 1). There were 16 subjects with PKU recruited for the study; only 12 completed the loading test, as seen in Figure 1. Seven patients successfully improved blood Phe control equal to or greater than the primary end goal set $(30 \%$ reduction) after 4 weeks of taking PheLNAA sachets. These seven patients showed between 32 and 90\% decline in blood Phe concentration from baseline throughout the study. Therefore, it is evident that the increased concentration of LNAA in the PheLNAA medical food greatly inhibited the transport of Phe in the Gl tract and to the BBB in these patients. Of the other five patients in our study, two achieved a decrease in blood Phe levels, but it was less than the $30 \%$ primary end goal set. The other three patients had an increase in blood Phe levels. Unfortunately, the patients who responded less to the treatment were the older aged children in our study group (data not shown). We speculate that the older aged children can manipulate their intake and follow the diet incoherently, whereas the younger children can follow their diet more strictly with their parents' help.

Overall, the PheLNAA medical food was ranked by the participants in this study, using their previous extensive experience, as having a better taste compared with their past formulas. Ideally, the PheLNAA medical food should be started at a younger age to assuage the non-compliance problem. If children become more familiar with the taste of their medical food at a younger 
age, it may be easier for them to accept it and adhere to their diet in the long run. When transitioning to the PheLNAA medical food from their old formula it is possible, if needed, to mix the two formulas for the first few days. This is only if the child is used to and demands the old formula; otherwise, it is advisable to completely switch to the new formula immediately. Of course, a dietitian should supervise this transition period to ensure that patients' daily nutritional needs are met. This would eliminate the problem of non-compliance that was experienced by some patients with this study. The patients with PKU would benefit from changing to PheLNAA in childhood, which should lead to improved blood Phe control.

\section{CONFLICT OF INTEREST}

The authors declare no conflict of interest.

\section{REFERENCES}

1 Scriver CR, Kaufman SHyperphenylalaninemia: phenylalanine hydroxylase deficiencyln:Scriver CR, Beaudet A, Sly WS et al. editors. The Metabolic and Molecular Bases of Inherited Disease, 8th edn. New York: McGraw Hill, 2001; 1667-1724.

2 Bickel H, Gerrard J, Hickmans E. Preliminary communication. Lancet 1953; 262: 812-813.

3 Azen C. Intellectual development in 12-year-old children treated for phenylketonuria. Arch Pediatr Adolesc Med 1991; 145: 35.

4 Fisch R, Matalon R, Weisberg S, Michals K. Phenylketonuria: current dietary treatment practices in the United States and Canada. J Am Coll Nutr 1997; 16: 147-151.

5 Gleason L, Michals K, Matalon R, Langenberg P, Kamath S. A treatment program for adolescents with phenylketonuria. Clin Pediatr 1992; 31: 331-335.

6 Michals K, Dominik M, Schuett V, Brown E, Matalon R. Return to diet therapy in patients with phenylketonuria. J Pediatr 1985; 106: 933-936.

7 Walter J, White F, Hall S, MacDonald A, Rylance G, Boneh A et al. How practical are recommendations for dietary control in phenylketonuria? Lancet 2002; 360: 55-57.

8 Burgard P, Rey F, Rupp A, Abadie V, Rey J. Neuropsychologic functions of early treated patients with phenylketonuria, on and off diet: results of a cross-national and cross-sectional study. Pediatr Res 1997; 41: 368-374.

9 Fisch RO, Chang PN, Weisberg S, Guldberg P, Guttler F, Tsai My. Phenylketonuria patients decades after diet. J Inherit Metab Dis 1995; 18: 426-427.

10 Griffiths P, Paterson L, Harvie A. Neuropsychological effects of subsequent exposure to phenylalanine in adolescents and young adults with early-treated phenylketonuria. J Intellect Dis Res 1995; 39: 365-372.

11 Lou H, Guttler F, Lykkelund C, Bruhn P, Niewieser A. A decreased vigilance and neurotransmitter synthesis after discontinuation of dietary treatment for phenylketonuria in adolescents. Eur J Pediatr 1985; 144: 17-20.

12 Michals K, Azen C, Acosta PB, Koch R, Matalon R. Blood phenylalanine and intelligence of ten-year-old children with phenylketonuria in the national collaborative study. J Am Diet Assoc 1988; 88: 1226-1229.

13 Pietz J, Dunckelmann R, Rupp A, Rating D, Meinck HM, Schmidt H et al. Neurological outcome in adult patients with early-treated phenylketonuria. Eur J Pediatr 1998; 157: 824-830.

14 Schmidt E, Rupp A, Burgard P, Pietz J, Weglage J, de Sonneville L. Sustained attention in adult phenylketonuria: the influence of the concurrent phenylalanine-blood-level. J Clin Exp Neuropsychol 1994; 16: 681-688.
15 Smith I, Lobascher M, Stevenson J, Wolff OH, Schmidt H, Grubel-Kaiser S et al. Effect of stopping the low phenylalanine diet on the intellectual progress of children with phenylketonuria. Br Med J 1978; 2: 723-726.

16 Smith I, Beasley MG, Ades AE. Effect on intelligence of relaxing the low phenylalanine diet in phenylketonuria. Arch Dis Child 1991; 66: 311-316.

17 Thompson AJ, Smith IL, Brenton D, Youl BD, Rylance G, Davidson DC et al. Neurological deterioration in young adults with phenylketonuria. Lancet 1990; 336: 602-605.

18 Thompson AJ, Tillotson A, Smith I, Kendall B, Moore SG, Brenton DP et al. Changes in phenylketonuria. Associations with dietary status. Brain 1994; 344: 87-90.

19 Kure S, Hou DC, Ohura T, Iwamoto H, Suzuki S, Sugiyama N et al. Tetrahydrobiopterin-responsive phenylalanine hydroxylase deficiency. J Pediatr 1999; 135: 375-378.

20 Christ SE, Moffitt AJ, Peck D, White DA. The effects of tetrahydrobiopterin (BH4) treatment on brain function in individuals with phenylketonuria. Neuroimage Clin 2013; 3: 539-547.

21 Matalon R, Michals-Matalon K, Bhatia G, Grechanina E, Novikov P, McDonald JD et al. Large neutral amino acids in the treatment of phenylketonuria (PKU). $J$ Inherit Metab Dis 2006; 29: 732-738.

22 Guzzetta V, Bonapace G, Dianzani I, Parenti G, Lecora M, Giannattasio S et al. Phenylketonuria in Italy: distinct distribution pattern of three mutations of the phenylalanine hydroxylase gene. J Inherit Metab Dis 1997; 20: 619-624.

23 National Institutes of Health Consensus Development Panel. National Institutes of Health Consensus Development Conference Statement: Phenylketonuria: Screening and Management, October 16-18, 2000. Pediatr 2001; 108: 972-982.

24 Hidalgo I, Borchardt R. Transport of a large neutral amino acid (phenylalanine) in a human intestinal epithelial cell line: Caco-2. Biochim Biophys Acta 1990; 1028: 25-30.

25 Choi T, Pardridge W. Phenylalanine transport at the human blood-brain barrier. J Biol Chem 1986; 261: 6536-6541.

26 Hargreaves K, Pardridge W. Neutral amino acid transport at the human bloodbrain barrier. J Biol Chem 1988; 263: 392-397.

27 Moller $\mathrm{H}$, Weglage J, Wiedermann D, Vermathen P, Bick U, Ullrich K. Kinetics of phenylalanine transport at the human blood-brain barrier investigated in vivo. Brain Res 1997; 778: 329-337.

28 Oldendorf $\mathrm{WH}$, Szabo J. Amino acid assignment to one of three blood-brain barrier amino acid carriers. Am J Physiol 1976; 230: 94-98.

29 Smith CB, Kang J. Cerebral protein synthesis in a genetic mouse model of phenylketonuria. Proc Natl Acad Sci USA 2000; 97: 11014-11019.

30 McDonald J, Gowda S, Matalon K, Grady J, Tyring S, Matalon R. Lowering blood phenylalanine concentration with large neutral amino acids (LNAA) supplementation in a mouse phenylketonuria model. J Inherit Metab Dis 2005; 28(Suppl 1): 22 (Abstract).

31 Matalon R, Surendran S, Michals-Matalon K, Tyring S, Quast M, Jinga W et al. Future role of large neutral amino acids in transport of phenylalanine into the brain. Pediatr 2003; 122: 1570-1574.

32 Matalon R, Michals-Matalon K, Bhatia G, Burlina AB, Burlina AP, Braga $C$ et al. Double blind placebo control trial of large neutral amino acids in treatment of PKU: effect on blood phenylalanine. J Inherit Metab Dis 2007; 30: 153-158.

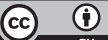

This work is licensed under a Creative Commons Attribution 4.0 International License. The images or other third party material in this article are included in the article's Creative Commons license, unless indicated otherwise in the credit line; if the material is not included under the Creative Commons license, users will need to obtain permission from the license holder to reproduce the material. To view a copy of this license, visit http://creativecommons.org/licenses/ by/4.0/

(c) The Author(s) 2017 